\title{
Perbandingan Kadar Fenolik Total Sari Rimpang Temu Giring (Curcuma heyneana) Segar dan Terfermentasi
}

\author{
Elrica Maggian Murelina, Ernanin Dyah Wijayanti \\ Program Studi D3 Farmasi \\ Akademi Farmasi Putra Indonesia Malang \\ Email: nanin.wijayanti@gmail.com
}

\begin{abstract}
Abstrak
Temu giring (Curcuma heyneana) telah lama digunakan oleh masyarakat Indonesia terutama untuk menjaga kesehatan kulit. Kandungan fenolik yang terdapat dalam temu giring memiliki khasiat sebagai antioksidan. Fermentasi diketahui dapat meningkatkan aktivitas antioksidan karena adanya peningkatan kadar senyawa fenolik. Tujuan penelitian ini untuk mengetahui perbandingan kadar senyawa fenolik total sari rimpang temu giring segar dan terfermentasi (Curcuma heyneana). Tahap penelitian ini meliputi penyaringan rimpang temu giring, fermentasi temu giring, identifikasi fitokimia, penetapan kadar fenolik total, analisis data dan membuat kesimpulan. Pembuatan sari temu giring dilakukan dengan menyari temu giring dengan air sampai didapatkan sari. Dilanjutkan dengan fermentasi menggunakan bakteri Lactobacillus bulgaricus selama 24 jam dengan suhu $37^{\circ} \mathrm{C}$. Pengujian organoleptis meliputi warna, bau, rasa dan $\mathrm{pH}$. Hasil $\mathrm{pH}$ sari segar dan terfermentasi mengalami penurunan. Pengujian identifikasi fitokimia temu giring segar dan terfermentasi positif mengandung fenolik dan flavonoid. Tahap penetapan kadar total fenolik total dengan metode FolinCiocalteu didapatkan sari temu giring segar sebesar 9.476 $2.04 \mathrm{mgGAE} / \mathrm{gram}$ dan sari temu giring terfermentasi sebesar $61.333 \pm 1.643 \mathrm{mgGAE} / \mathrm{gram}$. Kesimpulan dari penelitian ini adalah terdapat perbedaan kadar fenolik total sari temu giring segar dan terfermentasi yang mengalami peningkatan setelah difermentasi.
\end{abstract}

Kata-kata kunci: fenolik, fermentasi, temu giring

\begin{abstract}
Temu giring (Curcuma heyneana) has been used for a long time by Indonesian society to maintain the skin health. The phenolic content of temu giring has an efficacy as an antioxidant. Fermentation has been known to increase the antioxidant activity due to the increasing of phenolic content. This study aims to determine the comparison of total phenolic content of fresh and fermented temu giring (Cucuma heyneana) extract. The research procedures include the extract filtration, fermentation, phytochemical screening, total phenolic content determination, data analysis and drawing conclusion. Temu giring extract preparation was performed by filtering the temu giring with water until obtaining the extract. Then, the fermentation was conducted using Lactobacillus bulgaricus for 24 hours at $37^{\circ} \mathrm{C}$. The organoleptic testing, including dye, smell, taste and $\mathrm{pH}$, was performed. Finding shows that the fresh and fermented extract $\mathrm{pH}$ has decreased. The phytochemical screening of fresh and fermented temu giring indicates that it positively contains phenolic and flavonoid. From the total phenolic content determination by Folin Ciocalteu methods of fresh temu giring, the amount of 9.476 $\pm 2.04 \mathrm{mgGAE} / \mathrm{gram}$ was obtained and from the total phenolic content determination of fermented extract, the amount of $61.333 \pm 1.643 \mathrm{mgGAE} / \mathrm{gram}$ was obtained. It can be concluded that there is a difference of total phenolic content of fresh and fermented temu giring extract, which has increased after the fermentation.
\end{abstract}

Keywords: fermentation, phenolic, temu giring

\section{PENDAHULUAN}

Temu giring (Curcuma heyneana) telah dimanfaatkan untuk masyarakat terutama untuk menjaga kesehatan kulit. Beberapa manfaatnya antara lain adalah untuk merawat kulit, sebagai kosmetik, menjaga kesegaran tubuh, dan

didukung juga dengan aktivitasnya sebagai antioksidan dan antiinflamasi. Temu giring juga diketahui memiliki aktivitas antiaging sehingga berpotensi untuk digunakan sebagai fitokosmetik (Kusumawati et al. 2018). Pemanfaaatan temu

Murelina Dan Wijayanti, Perbandingan Kadar Fenolik Total Sari Rimpang Temu Giring (Curcuma Heyneana) Segar Dan Terfermentasi 
giring untuk kesehatan kulit didukung oleh kandungan senyawa aktif di dalamnya. Senyawa flavonoid dan kurkumin merupakan senyawa yang diketahui memiliki aktivitas antioksidan. Banyak penelitian yang telah menyatakan bahwa senyawa flavonoid memiliki potensi sebagai antioksidan karena memiliki gugus hidroksil yang terikat pada karbon cincin aromatik sehingga dapat menangkap radikal bebas (Hamid et al., 2010). Menurut Widyaningsih (2011) senyawa kurkumin juga memiliki sifat antioksidan. Alrawaiq and Abdullah (2014) menyatakan bahwa kemampuan kurkumin dalam menangkal radikal bebas didukung oleh adanya gugus fenol $(\mathrm{OH})$. Namun, sebagian besar senyawa fenolik, termasuk sulit diserap oleh tubuh manusia karena terdapat dalam bentuk terglikosilasi. Termasuk di dalamnya adalah senyawa flavonoid. Untuk mempermudah penyerapan sehingga bioaktivitasnya juga meningkat, maka perlu dilakukan pemecahan oleh enzim atau mikroba supaya senyawa lebih mudah dicerna atau diserap (Filannino et al., 2016). Pemecahan senyawa agar mudah diserap oleh tubuh dapat dilakukan dengan salah satu cara melalui proses fermentasi. Fermentasi yang paling banyak digunakan adalah fermentasi asam laktat. Jenis fermentasi ini menggunakan bakeri asam laktat yang aman dan manfaatnya terbukti, Lactobacillus bulgaricus yang umumnya digunakan untuk fermentasi yoghurt. Hasil penelitian Wijayanti et al., (2017) menunjukkan bahwa Lactobacillus bulgaricus mampu meningkatkan kadar fenolik buah tin sebesar $0,45 \%$. Namun, sejauh ini masih belum ada penelitian tentang kadar fenolik dari sari temu giring yang terfermentasi. Penelitian ini dilakukan untuk mengetahui adanya peningkatan kadar fenolik temu giring selama proses fermentasi.

\section{METODE}

Penelitian penetapan kadar total fenolik rimpang temu giring segar dan terfermentasi termasuk jenis penelitian eksperimental. Temu giring segar yang digunakan diperoleh dari Desa Donomulyo, Kabupaten Malang.

\section{Alat}

Alat yang digunakan adalah preparasi gelas dan penutupnya, timbangan analitik (OHAUS), $\mathrm{pH}$ meter (WTW), inkubator (Memmert), termometer, spektrofotometer UV-Vis (Genesis 2.0).

\section{Bahan}

Bahan yang digunakan adalah rimpang temu giring segar, aquades, bakteri Starter Lactobacillus bulgaricus, $\mathrm{HCl}$ pekat, kapas, etanol 70\%, serbuk $\mathrm{Mg}, \mathrm{NaOH} 10 \%$, Asam galat, reagen Folin Ciocalteau, $\mathrm{Na}_{2} \mathrm{CO}_{3}$.

\section{Cara Kerja}

\section{Fermentasi Rimpang Temu Giring}

Rimpang temu giring segar yang telah bersih dirajang, kemudian diblender dengan penambahan air (perbandingan 1:1). Sari rimpang temu giring segar dipasteurisasi selama 15 menit pada suhu $72^{\circ} \mathrm{C}$, kemudian ditambahkan starter bakteri Lactobacillus bulgaricus sebanyak 6\% (v/v) pada suhu sekitar $40^{\circ} \mathrm{C}$. Inkubasi dilakukan pada suhu $37^{\circ} \mathrm{C}$ selama 24 jam (dimodifikasi dari Wijayanti et al., 2017).

\section{Identifikasi Fitokimia}

Identifikasi fitokimia dilakukan dengan menguji beberapa senyawa fenolik, yaitu:

Flavonoid, sampel sari rimpang temu giring segar dan terfermentasi masing-masing sebanyak $1 \mathrm{~mL}$ dimasukkan ke dalam tabung reaksi, kemudian ditambahkan serbuk $\mathrm{Mg}$ dan 5 tetes $\mathrm{HCl}$ pekat. Positif mengandung flavonoid jika menghasilkan warna kuning, orange dan merah (dimofikasi dari Wijayanti and Setiawan, 2017).

Tanin, sari rimpang temu giring segar dan terfermentasi masing-masing sebanyak $1 \mathrm{~mL}$ dimasukkan ke dalam tabung reaksi. Ditambahkan aquades sebanyak $5 \mathrm{~mL}$ dan 1-2 tetes $\mathrm{FeCl}_{3} 5 \%$. Jika terjadi warna biru kehitaman atau hijau kehitaman menunjukkan adanya senyawa fenol (dimodifikasi dari Wijayanti dan Susilowati, 2017).

\section{Penetapan Kadar Fenolik}

\section{Penetapan Panjang Gelombang Maksimum}

Dibuat larutan baku induk asam galat 100 ppm. Dipipet larutan baku induk sebanyak $0,5 \mathrm{~mL}$ dan dimasukkan ke dalam labu ukur $10 \mathrm{~mL}$, ditambahkan reagen Folin Ciocalteau, kemudian dikocok dan didiamkan selama 5 menit. Ditambahkan larutan $\mathrm{Na}_{2} \mathrm{CO}_{3} 15 \%$, dikocok homogen dan didiamkan selama 5 menit. Selanjutnya ditambahkan akuades hingga $10 \mathrm{~mL}$ dan dibaca Panjang gelombang pada rentang $\lambda$ $500-900 \mathrm{~nm}$. 


\section{Penentuan Operating Time}

Larutan asam galat yang telah dibuat pada penentuan panjang gelombang maksimum diamati absorbansi pada panjang gelombang maksimum yang didapatkan tiap 5 menit selama 110 menit.

\section{Pembuatan Kurva Baku Asam Galat}

Larutan asam galat dengan konsentrasi 25, 30, 35, 40, 45 ppm masing-masing diambil sebanyak 0,5 $\mathrm{mL}$, ditambahkan dengan reagen Folin Ciocalteau sebanyak $1 \mathrm{~mL}$, selanjutnya ditambahkan $2 \mathrm{~mL}$ $\mathrm{Na}_{2} \mathrm{CO}_{3} 15 \%$ dan didiamkan selama operating time lalu dibaca absorbansi pada panjang gelombang maksimum.

\section{Penetapan Kadar Fenolik Total}

Sampel sari rimpang temu giring segar dan terfermentasi diambil masing-masing $0,5 \mathrm{~mL}$ ditambah dengan akuades hingga $10 \mathrm{~mL}$, kemudian dipipet $0,5 \mathrm{~mL}$ larutan induk sampel tersebut, dan ditambahkan reagen Folin Ciocalteau sebanyak $1 \mathrm{~mL}$, selanjutnya ditambahkan $2 \mathrm{~mL} \mathrm{Na}_{2} \mathrm{CO}_{3} 15 \%$. Larutan tersebut didiamkan selama operating time lalu dibaca absorbansi pada Panjang gelombang maksimum sebanyak 3 kali replikasi. Hasil pengukuran absorbansi larutan asam galat dibuat kurva kalibrasi hubungan antara konsentrai (C) dengan absorbansi (A) diperoleh persamaan garis linear dengan rumus $y=a x+b$.

\section{Analisis Data}

Data hasil penelitian dianalisis dengan Uji $t$ menggunakan SPSS.

\section{HASIL DAN PEMBAHASAN}

\section{Uji Organoleptis dan pH}

Hasil organoleptis dan $\mathrm{pH}$ menunjukkan adanya perbedaan pada sari rimpang temu giring segar dan terfermentasi. Adapun perbedaan hasil uji organoleptis dan $\mathrm{pH}$ dapat dilihat pada Tabel 1.

Adanya perubahan hasil pengamatan organoleptis dan $\mathrm{pH}$ dapat dikatakan bahwa fermentasi yang dilakukan berjalan lancar. Bentuk dari hasil fermentasi terdapat dua bagian meliputi bagian atas berupa air dan bagian bawah berupa endapan. Endapan tersebut berasal dari pati yang terkandung dari rimpang temu giring. Warna hasil pengujian organoleptis didapatkan lebih coklat pada hasil fermentasi diduga karena adanya perombakan senyawa yang terjadi selama proses fermentasi. Aroma yang didapatkan setelah fermentasi adalah aroma khas fermentasi, dan rasa yang dihasilkan lebih masam. Wijayanti and Setiawan (2017) menyatakan bahwa aktivitas bakteri asam laktat menyebabkan produksi asam yang ditunjukkan dengan perubahan warna dan penurunan $\mathrm{pH}$ menjadi lebih asam. Hal ini menunjukkan bahwa bakteri asam laktat yang digunakan sebagai starter mampu menggunakan gula pada sari rimpang temu giring sebagai substrat untuk pertumbuhannya

Tabel 1. Hasil Uji Organoleptis dan nilai $\mathrm{pH}$

\begin{tabular}{|c|c|c|}
\hline $\begin{array}{c}\text { Uji } \\
\text { organoleptis }\end{array}$ & $\begin{array}{c}\text { Sari } \\
\text { Rimpang } \\
\text { Temu } \\
\text { Giring } \\
\text { Segar }\end{array}$ & $\begin{array}{c}\text { Sari Rimpang } \\
\text { Temu Giring } \\
\text { Terfermentasi }\end{array}$ \\
\hline Warna & $\begin{array}{l}\text { Kuning } \\
\text { segar }\end{array}$ & $\begin{array}{c}\text { Kuning } \\
\text { kecoklatan }\end{array}$ \\
\hline Aroma & $\begin{array}{l}\text { Khas temu } \\
\text { giring }\end{array}$ & Khas fermentasi \\
\hline Rasa & Pahit & $\begin{array}{l}\text { Masam, sedikit } \\
\text { pahit dan sepat }\end{array}$ \\
\hline $\mathrm{pH}$ & 7,0 & 4,01 \\
\hline
\end{tabular}

\section{Identifikasi Fitokimia}

Pengujian fitokimia dilakukan untuk mengidentifikasi kandungan senyawa metabolit sekunder yang terdapat di dalam sampel sari rimpang temu giring segar dan terfermentasi. Adapun uji identifikasi fitokimia yang dilakukan meliputi senyawa flavonoid, fenol, dan kurkumin yang dapat dilihat pada Tabel 2.

Tabel 2. Hasil Identifikasi Fitokimia Sari Rimpang Temu Giring Segar dan Terfemetnasi

\begin{tabular}{lcc}
\hline $\begin{array}{c}\text { Uji } \\
\text { Fitokimia }\end{array}$ & $\begin{array}{c}\text { Sari Rimpang } \\
\text { Temu Giring } \\
\text { Segar }\end{array}$ & $\begin{array}{c}\text { Sari Rimpang } \\
\text { Temu Giring } \\
\text { Terfermnetasi }\end{array}$ \\
\hline Fenol & + & + \\
Flavonoid & + & + \\
\hline
\end{tabular}

Berdasarkan hasil uji Identifikasi fitokimia sampel sari temu giring segar dan terfermentasi positif mengandung senyawa fenol, kurkumin, dan flavonoid.

Identifikasi fitokimia fenol sari rimpang temu giring sebelum fermentasi memiliki warna merah hijau pekat dan sari terfermentasi hijau kehitaman. Kedua sampel tersebut memiliki 
perbedaan warna namun positif mengandung fenol dengan pereaksi $\mathrm{FeCl}_{3}$. Pereaksi $\mathrm{FeCI}_{3}$; digunakan secara luas untuk mengidentifikasi senyawa fenol termasuk tanin. Oleh sebab itu dapat terjadi kemungkinan bahwa hasil positif juga dapat diberikan oleh senyawa fenolik lain dalam sampel (Sangi et al., 2008).

Identifikasi fitokimia flavonoid menunjukkan adanya perubahan warna sari rimpang temu giring segar dan terfermentasi menjadi lebih pekat karena adanya proses fermentasi dimana senyawa flavonoid menjadi lebih banyak. Identifikasi fitokimia pada senyawa flavonoid menggunakan uji BateSmite yang ditunjukkan dengan adanya warna merah. Penambahan $\mathrm{HCl}$ pekat dalam uji flavonoid bertujuan untuk menghidrolisis flavonoid menjadi aglikonnya, yaitu dengan menghidrolisis O-glikosil. Glikosida berupa gula yang biasa dijumpai yaitu glukosa, galaktosa dan raminosa. Setelah penambahan serbuk $\mathrm{Mg}$ akan terjadi proses reduksi sehingga menghasilkan senyawa kompleks yang berupa garam flavilium yang menyebabkan terbentuknya warna merah pada flavonoid (Latifah, 2015). Identifikasi fitokimia kurkumin dalam sampel sari rimpang temu giring memiliki persamaan warna ditandai dengan warna merah. Kurkumin yang terkandung adalah senyawa yang memberikan warna kuning dalam tanaman rimpang yang jika direaksikan dengan asam borat menjadi kompleks warna merah.

\section{Penetapan Kadar Fenolik}

Penetapan kadar fenolik total menggunakan metode Folin Ciocalteau. Metode ini merupakan metode yang paling umum digunakan untuk menentukan kandungan fenolik total dalam tanaman dengan pertimbangan bahwa dengan teknik ini pengerjaannya lebih sederhana dan reagen Folin Ciocalteau digunakan karena senyawa fenolik dapat bereaksi dengan Folin membentuk larutan yang dapat diukur absorbansinya. Larutan standar yang digunakan adalah asam galat yang merupakan salah satu fenolik alami dan stabil.

Analisis kandungan fenolik total menggunakan metode Folin-Ciocalteu yang absorbansinya diukur pada panjang gelombang $765 \mathrm{~nm}$ (Putri dan Wuryandari, 2018). Panjang gelombang maksimum yang diperoleh yaitu $775 \mathrm{~nm}$. Selanjutnya dilakukan pengukuran absorbansi larutan standar asam galat dari beberapa konsentrasi yang diukur pada panjang gelombang maksimum yang diperoleh. Hasil pengukuran absorbansi larutan standar asam galat dibuat kurva kalibrasi yang dapat dilihat pada Gambar 1.

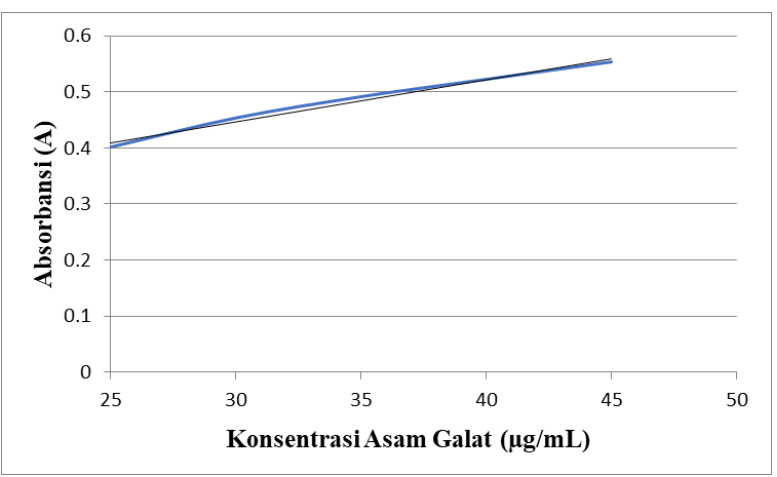

Gambar 1. Kurva Standar Asam Galat

Persamaan regresi linear yang diperoleh yaitu $\mathrm{y}=0,0075 \mathrm{x} 0,2229$ dengan koefisien korelasi $(\mathrm{r})$ 0,9865 . Penetapan kadar fenol total sari temu giring segar dan terfermentasi dilakukan sebanyak 3 kali replikasi. Penggunaan Lactobacillus bulgaricus pada fermentasi sari rimpang temu giring mampu menghasilkan peningkatan kadar fenolik total. Sebelum difermentasi total kandungan fenolik sari temu giring sebesar $9.476 \pm 2,042 \mathrm{mgGAE} / \mathrm{gram}$ dan setelah difermentasi sebesar $61.333 \pm 1,643 \mathrm{mgGAE} /$ gram. Berdasarkan hasil uji t, kadar fenolik total sari rimpang temu giring sebelum dan sesudah fermentasi berbeda secara signifikan. Kadar fenolik total sari rimpang temu giring setelah proses fermentasi lebih tinggi dari pada sebelum fermentasi, sehingga menunjukkan adanya peningkatan kadar fenolik total.

Peningkatan kadar fenolik total pada hasil fermentasi dapat disebabkan oleh reaksi enzimatik pada substrat, sehingga melepaskan senyawa fenolik yang agak tinggi sebagai produk akhir. Fermentasi alami menggunakan mikroorganisme merangsang reduksi $\mathrm{pH}$ sehingga beberapa enzim yang terlibat dalam hidrolisis polifenol kompleks diaktifkan sehingga menghasilkan polifenol aktif, sederhana dan lebih tinggi. (Wijayanti et al., 2017).

Hasil penelitian ini sejalan dengan hasil beberapa penelitian lain yang mengkaji tentang pengaruh fermentasi terhadap kadar fenolik total, antara lain peningkatan kadar fenolik total pada kombucha daun gaharu (Nurmiati dan Wijayanti, 2018), teh herbal Malaysia (Ibrahim et al., 2014) serta jaruk tigarun (Nazarni et al., 2016). 


\section{KESIMPULAN}

Berdasarkan hasil yang diperoleh pada penelitian ini, dapat disimpulkan bahwa terdapat perbedaan kadar fenolik total sari rimpang temu giring (Curcuma heyneana) segar dan terfermentasi oleh bakteri Starter Lactobacillus bulgaricus. Hasil Analisa uji t diperoleh nilai signifikan yaitu $0,031<0,05$ maka dilihat dari hipotesis menyatakan bahwa $\mathrm{H}_{1}$ diterima, yang berarti terdapat perbedaan perbandingan kadar fenolik total sari temu giring segar dan terfermentasi.

\section{DAFTAR RUJUKAN}

Alrawaiq, N.S. \& A. Abdullah. 2014. A Review of Antioxidant Polyphenol Curcumin and Its Role in Detoxification. International Journal of PharmTech Research. Vol. 6 (1): 280-289.

Filannino, P., I. Cavoski, N. Thlien, O. Vincentini, M.D. Angelis, M. Silano, M. Gobbetti \& R.D. Cagno. 2016. Lactic Acid Fermentation of Cactus cladodes (Opuntia ficus-india L.) Generates Flavonoid Derivatives with Antioxidant and Anti-Inflammantory Properties. PLoS ONE 11(3): 1-22.

Hamid, A.A., O.O. Aiyelaagbe, L.A. Usman, O.M. Ameen \& A. Lawai. 2010. Antioxidants: Its Medicinal and Pharmacological Applications. African Jurnal of Pure and Applied Chemistry Vol. 4 (8): 142151.

Ibrahim, N. A., S. Mustafa \& A. Ismail. 2014. Effect of Lactic Fermentation on The Antioxidant Capacity of Malaysian Herbal Teas. International Food Research Journal 21(4): 1483-1488.

Kusumawati, I., K.O. Kurniawan, S. Rullyansyah, T.A. Prijo, R. Widyowati, J. Ekowati, E.P. Hestianah, S. Maat \& K. Matsunami. 2018. Antiaging properties of Curcuma heyneana Valeton \& Zipj: A scientific approach to its use in Javanese tradition. Journal of Ethnopharmacology. Volume 225: 64-70

Latifah. 2015. Identifikasi Golongan Senyawa Flavonoid dan Uji Aktivitas Antioksidan pada Ekstrak Rimpang Kencur Kaempferia galanga L. Dengan Metode DPPH. Skripsi. UIN Malang.

Nazarni, R., D. Purnama, S. Umar, \& H. Eni. 2016. The Effect Of Fermentation On Total Phenolic, Flavonoid And Tannin Content And Its Relation To Antibacterial Activity In Jaruk Tigarun (Crataeva nurvala, Buch HAM).
International Food Research Journal 23 (1): 309315.

Nurmiati \& E.D. Wijayanti. 2018. Perbandingan Kadar Fenolik Total Antara Seduhan Daun Gaharu Dan Kombucha Daun Gaharu (Aquailaria malaccensis). Journal Cis-Trans (JCT) Volume 2 (1): 6-11

Putri, O.K. \& W. Wuryandari. 2018. Efek Suhu Penyeduhan Daun Tin (Ficus carica) Segar dan Kering Terhadap Kadar Fenolik Total. Jurnal Teknologi Pangan. Vol. 12 (2): 1-6.

Sangi, M., M.R.J. Runtuwene, H.E.I. Simbala \& V.M.A. Makang. 2008. Analisis Fitokimia Tumbuhan Obat di Kabupaten Minahasa Utara. Chem. Prog. Vol. 1. No. 1.

Widyaningsih, W. 2011. Efek Ekstrak Etanol Rimpang Temu Giring (Curcuma heyneana Val) Terhadap Kadar Trigliserida. Jurnal Ilmiah Kefarmasian Vol 1 (1): 55-65.

Wijayanti, E. D. \& E. Susilowati. 2017. Eksplorasi Ekstrak Etanol Beberapa Tumbuhan Berpotensi Sebagai Antiketombe. Jurnal Riset Sains dan Teknologi. Volume 1 (2): 75-81

Wijayanti, E.D. \& N.C.E. Setiawan. 2017. The Effect of Lactic Acid Fermentation on Fig (Ficus carica) Fruit Flavonoid. Journal of Biological Researches, 23 (1), 39-44

Wijayanti, E.D., N.C.E. Setiawan \& J.P. Cristi. 2017. Effect of Lactic Acid Fermentation on Total Phenolic Content and Antioxidant Activity of Fig Fruit Juice (Ficus carica). Advances in Health Sciences Research Vol 3: 282-289 